\title{
Alternativas tecnológicas para recuperar la cobertura vegetal en la zona de Rubiales en Puerto Gaitán-Meta
}

\section{Technology alternatives to recover the vegetation coverage in the Rubiales, Puerto Gaitán-Meta}

\author{
Beltrán Guarnizo Laura ${ }^{1}$ y Pérez López Otonie ${ }^{2}$ \\ ${ }^{1}$ I. A. Universidad de los Llanos y ${ }^{2}$ I. A. Investigador Profesional Asociado,
} CORPOICA

\section{operez@corpoica.org.co}

Recibido 12 de Diciembre 2013, Aceptado 11 de Abril 2014

\section{RESUMEN}

El objetivo de este trabajo fue validar y aplicar metodologías de evaluación y desarrollo de tecnologías para la restauración de suelos intervenidos por la empresa petrolera "Rubiales" a través del ajuste de modelos o arreglos que involucran practicas y sistemas de labranza conservacionista y la utilización de especies herbáceas, arbustivas y arbóreas, para lo cual se seleccionaron materiales vegetales con rápido potencial de crecimiento y persistencia, para contribuir a la recuperación de la cobertura vegetal permanente. También se definieron prácticas de manejo agronómico y sistemas de labranza conservacionista para intervención de procesos con el fin de volver a cubrir con vegetación a zonas de Puerto Gaitán, ubicada en la altillanura plana colombiana, haciendo de manera simultánea transferencia de tecnología a usuarios y productores. La incorporación parcial de insumos y de fuentes de fosforo como el calfos en el proceso de ajuste de las prácticas de establecimiento, dieron buenos resultados en las áreas que fueron nuevamente cubiertas por vegetación, mejorando el suministro o disponibilidad de nutrientes para las plantas en diferentes fases de desarrollo. Los materiales forrajeros seleccionados: $B$. decumbens, $B$. dictyoneura y $B$. humidicola, demostraron adaptación a las condiciones edafoclimáticas de la zona. La fertilización temprana de los lotes con 
fuentes solubles puede ayudar a contrarrestar efectos negativos como la escorrentía sobre las plántulas, pues si se logra un desarrollo más rápido y vigoroso de estas, se mejora el anclaje y se incrementa la población de plantas por unidad de área; teniendo en cuenta el momento de la fertilización, la cual debe realizarse entre los 30 a 45 días después de la siembra. Sin embargo, esta labor está determinada por las condiciones de humedad del suelo asociadas a la precipitación en las áreas que nuevamente fueron cubiertas por vegetación. Con las prácticas utilizadas y con el uso de estas tres especies se logró la oportuna entrega de varios lotes a los 120 días con criterio del 70\% mínimo de cobertura, demostrando adaptación a las condiciones edafoclimáticas de la zona.

Palabras clave: Recuperación de suelos, vegetación, gramíneas.

\begin{abstract}
The objective of this study was to validate and apply methodologies for evaluation and development of technologies for the restoration of soils affected by the oil company "Rubiales" through fitting models or arrangements involving practices and conservation tillage systems and the use of species herbaceous, shrub and tree, which plant materials were selected, with rapid growth potential and continuing to contribute to the recovery of permanent vegetative cover. Agronomic management practices and conservation tillage systems for intervention revegetation processes in order to return to areas covered with vegetation of Puerto Gaitan, located on colombian altillanura simultaneously making technology transfer to users and producers of this area is also defined. The partial incorporation of inputs and sources of phosphorus as calfos in the process of setting practices of establishment, were successful in areas that were again covered by vegetation, improving the supply or availability of nutrients to plants at different stages development. Selected forage materials were: B. decumbens, B. dictyoneura and $B$. humidicola, demonstrated adaptation to soil and climatic conditions of the area. Early fertilization lots with soluble sources, can help counteract negative effects on runoff seedlings, because if a quick and vigorous development of these
\end{abstract}


accomplished, the anchor and higher plant population per unit area is increases; considering the moment of fertilization, which should be conducted between 30 to 45 days after planting. However, this work is determined by the moisture conditions associated with precipitation in areas that were again covered by ground vegetation. With the practices used and the use of these three species timely delivery of various lots within 120 days with $70 \%$ criterion of minimum coverage was achieved, demonstrating adaptation to soil and climatic conditions of the area.

Keywords: Recovery of soils, vegetation, grasses

\section{INTRODUCCIÓN}

El municipio de Puerto Gaitán pertenece a la región de la altillanura Colombiana, localizado aproximadamente entre $3^{\circ} 05^{\prime}$ y $4^{\circ} 08^{`}$ latitud norte y a $71^{\circ} 05^{\prime}$ y $72^{\circ} 30^{\prime}$ longitud oeste y está ubicado a 207 kilómetros de la ciudad de Villavicencio, al oriente del departamento (Pulido et al., 2006). Se constituye en el municipio de mayor extensión territorial del Meta, donde se encuentran 1300 hectáreas en las que se observa procesos de degradación ambiental y paisajística, debido a la intervención del campo petrolero "Rubiales" y su área de influencia. Es de anotar, que en esta zona los suelos presentan restricciones físicas, químicas y biológicas, que por estar ubicados en condiciones orográficas onduladas, los hace altamente susceptibles a la erosión, lo cual se ha venido intensificando por las actividades petroleras. Con la situación planteada se justifica la búsqueda de opciones tecnológicas para mejorar la calidad y el manejo del suelo y de coberturas vegetales tendientes a la recuperación del entorno evitando los riesgos de erosión y el impacto sobre el medio ambiente.

La remoción de la cobertura vegetal y el suelo para la extracción de arrecife, un material petroférrico técnicamente denominado plintita y utilizado en las obras de ingeniería civil para la construcción y adecuación de carreteras, campamentos e infraestructura de almacenamiento y distribución de hidrocarburos, ha generado procesos de degradación ambiental y paisajística en las zona, que requieren la formulación y evaluación de alternativas de manejo que permitan la recuperación 
de la cobertura vegetal, atenuando de esta manera los efectos ambientales de la actividad petrolera, además se pueden convertir en alternativas productivas para la región. Las áreas intervenidas y los taludes generados en estas obras presentan escasas coberturas vegetales y el establecimiento de la vegetación, tanto de forma natural como a en las restauraciones es muy lento. La propuesta se enmarca en las políticas de responsabilidad social de las empresas que están al frente de la producción de crudo, y que por orden legal están obligados a generar y aplicar planes de manejo ambiental para estas áreas (Jorba et al., 2007).

El estudio de los factores que limitan la colonización vegetal en estas áreas degradadas puede ayudar a mejorar las técnicas para recuperar la capa vegetal, permitiendo optimizar el uso de recursos según las necesidades y elaborar planes con posibilidades de éxito (Tormo et al. 2009). Al igual que en otros ambientes, en los taludes de carreteras la colonización se ve limitada por la capacidad de dispersión de algunas semillas, por lo que estas laderas son colonizadas principalmente por especies provenientes de áreas cercanas.

\section{ANTECEDENTES}

En la última década se ha venido incrementando la actividad minera relacionada con la explotación petrolera especialmente en el sector de Rubiales en Puerto Gaitán, esto ha generado procesos de afectación al medio ambiente. La mayoría de las actividades de desarrollo económico emprendidas por el hombre son, en mayor o menor medida, agresivas para la naturaleza (Jaramillo, 2002), entre ellas, las que conllevan el movimiento de grandes volúmenes de tierra, como en la minería y obras de infraestructura vial, que ocasionan un importante impacto visual, constituyendo una agresión global de tal magnitud, que afecta a casi todos los elementos que integran el medio natural, no sólo al paisaje (IGAC, 2003), puesto que hay destrucción de la cubierta vegetal y de la fauna asociada, pérdida de suelo, aunque en pocos casos se retira la capa superior del yacimiento, ésta no se conserva para ser utilizada posteriormente en las labores de restauración; también se cambia la geomorfología del terreno, en sus perfiles siendo visible 
escombreras y huecos, generando contaminación de aguas por lavado de impurezas y minerales (aguas ácidas); contaminación del aire por liberación de partículas de polvo y sustancias tóxicas como emisiones de azufre en la minería del carbón, por ejemplo, y otros residuos perjudiciales los cuales provienen de sustancias peligrosas utilizadas en procesos de extracción de minerales (Maya, 2012). En ausencia de cubierta vegetal las áreas mineras sufren procesos de lixiviación y erosión, contaminando y matando ríos, arroyos, acuíferos y zonas adyacentes.

Frente a la desestabilización de los suelos por medios físicos, la alternativa es cubrirlos con vegetación. Los espacios afectados por actividades mineras deben integrarse en su entorno natural según exige la legislación nacional vigente. Las siembras representan la actuación de revegetación más extendida en el sector minero (Jorba et al., 2007). Con la introducción de especies de cobertura se busca proporcionar servicios al agroecosistema como: evitar erosión, captura y prevención de pérdidas de nutrientes del suelo e incremento de carbono, fijación del nitrógeno, y mejoramiento de sus características físico químicas, por el aumento de la diversidad de organismos benéficos evitando el ataque de plagas (Teasdale, 2004; Ernst, 2004; Navarro et al., 2007).

Los cultivos de cobertura son un recurso importante para la gestión favorable y sustentable de los sistemas de producción agropecuarios, puesto que reducen o evitan la erosión de suelos sin estructura, con alta acidez y pobres en materia orgánica, ocasionada por altas precipitaciones y fuertes vientos (Jaramillo, 2002), el restablecimiento de la cobertura vegetal presenta limitaciones debido a que en la región, se dispone de escasa información sobre esta problemática, por lo cual es importante comprender los factores que controlan el restablecimiento de la cobertura vegetal en las áreas descubiertas y taludes, para así desarrollar alternativas apropiadas para favorecer el proceso de revegetación. La importancia de la investigación consiste en favorecer el proceso de cobertura vegetal. 


\section{Suelos de la altillanura}

Los suelos presentan un alto grado de evolución, que se manifiesta en el predominio de cuarzo en la fracción arena y de caolinita y óxidos y hierro en la fracción arcilla, $\mathrm{pH}$ acido, altos niveles de aluminio en el complejo de intercambio, también presentan una fase continua de plintita en los primeros $30 \mathrm{~cm}$ de la superficie, este componente es una mezcla de arcilla y cuarzo residual con alta concentración de hierro y aluminio, se endurece irreversiblemente cuando se expone a ciclos alternos de humedecimiento y secamiento, por acción directa de los rayos solares. Por su alto grado de meteorización presentan una fuerte acidez y han perdido casi toda su capacidad para suplir nutrimentos a las plantas (CIAT, 2001). Siendo sus arcillas de baja capacidad de intercambio catiónico, están ocupados en su mayoría por el aluminio (tóxico) con saturaciones superiores al $70 \%$ limitando el desarrollo de cultivos por la toxicidad de este elemento. A su vez; presentan deficiencia de nutrientes esenciales como nitrógeno, fosforo, calcio y magnesio, potasio y azufre. El fosforo $(P)$ es el nutrimento mas limitante para el establecimiento de pasturas (Tabla 1) (Rincón, 1999; Pérez et al., 2009).

Tabla 1. Características químicas de los suelos de la altillanura colombiana

\begin{tabular}{ccc}
\hline Parámetro & Altillanura disectada & Altillanura plana \\
\hline $\mathrm{pH}$ & $4.4-4.9$ & $4.5-5.0$ \\
$\mathrm{M} . \mathrm{O} .(\%)$ & $1.4-2.4$ & $1.8-3.7$ \\
$\mathrm{P}(\mathrm{ppm})$ & $1.0-2.0$ & $1.0-4.0$ \\
$\mathrm{Ca}(\mathrm{me} / 100 \mathrm{~g})$ & $0.17-0.25$ & $0.20-0.58$ \\
$\mathrm{Mg}(\mathrm{me} / 100 \mathrm{~g})$ & $0.05-0.09$ & $0.07-0.19$ \\
$\mathrm{~K}(\mathrm{me} / 100 \mathrm{~g})$ & $0.04-0.06$ & $0.02-0.09$ \\
$\mathrm{Na}(\mathrm{me} / 100 \mathrm{~g})$ & $0.08-0.20$ & $0.07-0.26$ \\
$\mathrm{Al}(\mathrm{me} / 100 \mathrm{~g})$ & $1.4-1.7$ & $1.5-3.5$ \\
$\mathrm{~B}(\mathrm{ppm})$ & $0.10-0.20$ & $0.14-0.36$ \\
$\mathrm{Cu}(\mathrm{ppm})$ & $0.2-0.3$ & $0.4-0.9$ \\
$\mathrm{Zn}(\mathrm{ppm})$ & $0.3-0.6$ & $0.4-1.0$ \\
$\mathrm{Fe}(\mathrm{ppm})$ & $15-60$ & $10-460$ \\
$\mathrm{Mn}(\mathrm{ppm})$ & $0.5-5.4$ & $0.8-9.2$ \\
\hline
\end{tabular}

Fuente: Rincón, 1999 


\section{Requerimientos nutricionales de especies forrajeras tropicales}

Para obtener buen desarrollo de los pastos y alta producción de forraje, se han establecido condiciones adecuadas de fertilidad en rangos de contenido de nutrientes en el suelo, para pastos adaptados de menor exigencia y para pastos adaptados con mayores requerimientos de minerales (Tabla 2). Con este contenido de nutrientes en los suelos, los cual permitirá mejorar los rendimientos y ofrecer un forraje de mejor calidad (Rincón, 1999).

Tabla 2. Rangos de contenido de minerales en los suelos para el buen desarrollo de pastos en la altillanura colombiana

\begin{tabular}{ccc}
\hline Mineral & Pastos menos exigentes & Patos exigentes \\
\hline $\mathrm{P}(\mathrm{ppm})$ & $5-10$ & $10-15$ \\
$\mathrm{~K}(\mathrm{me} / 100 \mathrm{~g})$ & $0.10-0.12$ & $0.15-0.20$ \\
$\mathrm{Ca}(\mathrm{me} / 100 \mathrm{~g})$ & $0.5-1.0$ & $1.5-2.0$ \\
$\mathrm{Mg}(\mathrm{me} / 100 \mathrm{~g})$ & $0.12-0.20$ & $0.3-0.4$ \\
$\mathrm{~S}(\mathrm{ppm})$ & $15-20$ & $20-25$ \\
$\mathrm{Zn}(\mathrm{ppm})$ & $1.0-1.5$ & $1.5-2.0$ \\
$\mathrm{Cu}(\mathrm{ppm})$ & $1.0-2.0$ & $2.0-3.0$ \\
$\mathrm{~B}(\mathrm{ppm})$ & $0.5-1.0$ & $1-1.5$ \\
\hline
\end{tabular}

Fuente: Rincón, (1999). Pastos exigentes: Panicum spp, Brachiaria brizantha, Brachiaria toledo. Pastos menos exigentes: Brachiaria decumbens, Brachiaria humidicola, Brachiaria dyctioneura

La aplicación de fertilizantes al establecimiento de las praderas tiene por objeto proveer los elementos nutritivos deficientes en el suelo para asegurar un desarrollo rápido y vigoroso de las plantas, y una alta producción de forraje de las praderas (Faria, 2006). Esta debe realizarse teniendo en cuenta los resultados del análisis de suelos y los requerimientos de la especie forrajera a establecer. Para suelos ácidos, con alta saturación de aluminio (Al), como son los de la región, las fuentes de fósforo, calcio $(\mathrm{Ca})$ y magnesio $(\mathrm{Mg})$ deben ser de lenta solubilidad como: las rocas fosfóricas (18-22\% de $\mathrm{P}_{2} \mathrm{O}_{5}$ ), y cal dolomita, como fuente de $\mathrm{Ca}$ y de Mg (Zapata, 2003). Otras fuentes importantes de calcio y fosforo de mayor solubilidad que la roca fosfórica son el abono paz del rio y las rocas parcialmente aciduladas las cuales han sido tratadas con ácido para mejorar la disponibilidad de 
fosforo. También se recomienda el yeso agrícola que proporciona calcio y azufre en forma de sulfato, que es el compuesto como la planta lo absorbe por las raíces (Osorno, 2012). Este compuesto junto con la cal dolomita cumple la función de reducir la saturación de aluminio en el suelo y aumentar los contenidos de bases intercambiables ( $\mathrm{Ca}, \mathrm{Mg}, \mathrm{K}$ ) sin embargo, la principal ventaja del yeso agrícola es el movimiento que tiene el calcio en el suelo cuando está unido al sulfato, permitiendo su mayor disponibilidad a niveles más profundos favoreciendo el desarrollo de raíces de los pastos (Gómez et al., 2001).

Con respecto a la fertilización con elementos menores, investigaciones que se realizaron en Carimagua (CIAT, 1994), demostraron que en gramíneas y leguminosas forrajeras no se obtiene efecto positivo con la aplicación de micronutrientes sobre la disponibilidad de forraje. La cantidad de boro y manganeso disponibles bajo condiciones de sabana nativa es adecuada para el establecimiento de pastos, mientras que las aplicaciones de zinc y cobre al suelo mejoran su contenido en las gramíneas, lo cual es importante ya que sin la aplicación de estos microelementos los niveles serian inferiores a los requeridos por el animal, por lo tanto, la fertilización de mantenimiento con zinc y cobre es importante en praderas de gramíneas puras (Rincón, 2006).

\section{Características de especies forrajeras}

Para las condiciones naturales de baja fertilidad de estos suelos se han evaluado y seleccionado pastos principalmente del genero Brachiaria sobresaliendo el Brachiaria decumbens cv. Amargo, Brachiaria humidicola cv. Dulce y el Brachiaria dictyoneura cv. Llanero; especies que con mínimos insumos han permitido aumentar la productividad, sin embargo, para conservar su potencial de crecimiento y persistencia, y evitar su degradación, es necesario hacer fertilización de establecimiento y mantenimiento. Las gramíneas y leguminosas que se recomiendan en cada región, son el producto del proceso investigativo desarrollado por varias instituciones públicas y privadas del país en las dos últimas 
décadas, con base en las experiencias de manejo y respuesta productiva (CIAT, 1988).

Brachiaria decumbens. Nombres comunes: pasto amargo, pasto peludo, brachiaria. Originario de África Ecuatorial, se adapta con éxito en Australia, el Caribe, Brasil y en Colombia (Figura 1). Se introdujo a Colombia en 1953, crece bien en regiones de baja fertilidad con sequias prolongadas y suelos bien drenados del piedemonte de la altillanura colombiana (Rincón, 2011). Se recupera rápidamente después del pastoreo, compite bien con las malezas y soporta la quema. No crece bien en zonas inundables y es muy susceptible al ataque del "mión o salivazo" (Aeneolamia sp). Crece bien entre 400 y 1800 msnm, con una precipitación de 1000 a $3500 \mathrm{~mm} /$ año y temperaturas superiores a los $19{ }^{\circ} \mathrm{C}$. (Ramírez et al., 2012).

Se puede establecer con material vegetativo o por medio de semilla sembrando a una distancia entre tallos o cepas de 80 a $100 \mathrm{~cm}$ a una profundidad de 8 a $12 \mathrm{~cm}$ en el suelo. Cuando se usa semilla, la siembra puede efectuarse con voleadora, sembradora de precisión, encaladora o en forma manual al voleo. Se recomienda utilizar de 2 a $3 \mathrm{~kg}$ de semilla escarificada con 90 a 95\% de pureza (Belalcazar et al., 1995).

Las ventajas de esta especie son: rápido establecimiento, buena producción y calidad de semilla, fácil propagación, se asocia bien con leguminosas, posee un adecuado valor nutritivo y consumo, soporta la quema y tiene buena recuperación. Sus desventajas son: susceptibilidad al salivazo, es fotosensibilizador principalmente en animales jóvenes, los equinos no lo consumen, no soporta suelos húmedos y es lenta su recuperación y tiene bajo vigor en suelos arenosos (Rincón, 2011).

Brachiaria dictyoneura. Nombre común: Pasto llanero. Originario de África tropical, se adapta bien a condiciones de suelos ácidos, de baja fertilidad, con textura de franco a arcillosos y de buen drenaje (Figura 2). Tiene buen comportamiento en regiones tropicales desde 0 hasta $1800 \mathrm{msnm}$, con 
precipitaciones entre 1500 y $3500 \mathrm{~mm}$ al año (Rincón, 2011). Esta especie se caracteriza por una cobertura inicial baja como consecuencia de la latencia prolongada de la semilla. Una vez alcanzado el óptimo establecimiento, esta especie proporciona una protección eficiente del suelo por su crecimiento estolonífero y rizomatoso. Persiste bajo pastoreo excesivo, debido a que sus nudos de crecimiento son de corta longitud (Belalcazar et al., 1995).

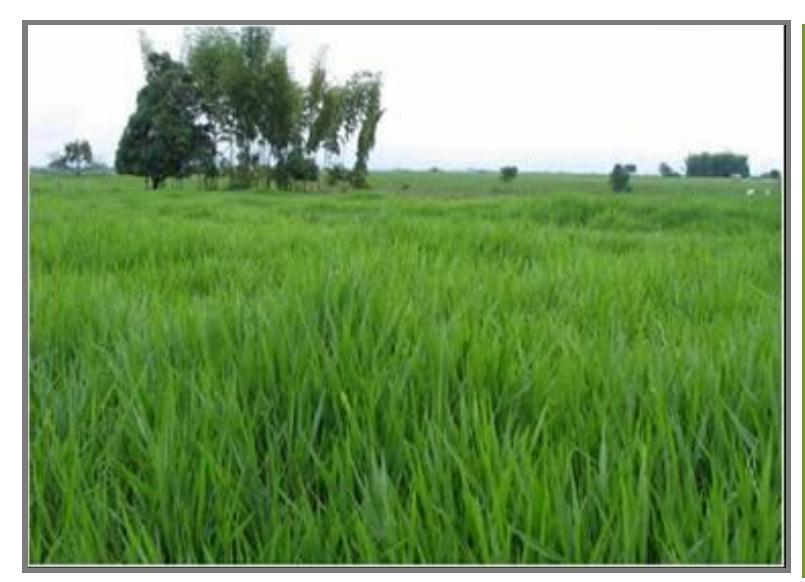

Figura 1. Pasto Brachiaria decumbens

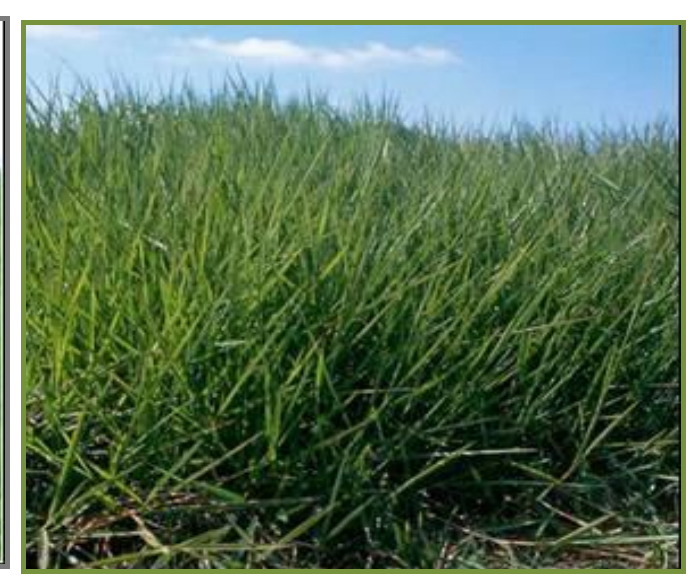

Figura 2. Pasto Brachiaria dictyoneura

Esta especie se puede sembrar con semilla cariópside o por material vegetativo, utilizando cepas o estolones y en este último caso el establecimiento es lento, debido al escaso enraizamiento. La cantidad de semilla o de material vegetativo depende del sistema de siembra; cuando se utiliza semilla la cantidad depende de su calidad (pureza y germinación) y de las condiciones del terreno. Se recomienda utilizar de 3 a $4 \mathrm{~kg} / \mathrm{ha}$ de semilla escarificada con 90 a 95\% de pureza, y semilla pura germinable superior al 10\% (Franco et al., 2005).

El pasto llanero se adapta bien a condiciones de suelos ácidos y de baja fertilidad, es tolerante a la sequia y se recupera bien después de la quema, tolera el ataque de cercópidos, tiene buena compatibilidad con leguminosas tipo Arachis pintoi, con buena palatabilidad y valor nutritivo medio, su producción de semilla es buena con crecimiento invasor. Es mejor establecerlo con semilla porque es susceptible al ataque de hormigas, tiene un escaso enraizamiento de estolones, además se requiere mayor densidad de siembra en áreas con alto potencial de malezas, la 
latencia de su semilla es prolongada y es la más difícil de romper del genero Brachiaria, además no tolera encharcamientos prolongados (Olivera et al., 2006).

Brachiaria humidicola. Nombre común: Pasto dulce. Es nativo de África tropical oriental y sur oriental, en zonas con alta precipitación (Figura 3). Introducido a Colombia en 1973 por el CIAT, ha sido evaluado en diferentes ecosistemas entre estos la altillanura colombiana (Belalcazar et al., 1995). Crece bien en regiones tropicales desde el nivel del mar hasta $1800 \mathrm{msnm}$ y precipitación pluvial de 1500 a $4000 \mathrm{~mm}$ al año. Se adapta a un rango amplio de ecosistemas, con buen comportamiento en suelos húmedos de franco arenosos a arcillosos con buen drenaje, ácidos y pobres en minerales, tolerante a la sombra y por su fuerte y alto crecimiento estolonífero puede ser usado como control de la erosión, por lo que no se puede asociar con algunas leguminosas (Keller et al., 1996; Olivera et al., 2006).

Esta gramínea requiere para un buen establecimiento 3 a $4 \mathrm{~kg} / \mathrm{ha}$ de semilla escarificada, con germinación superior al $22 \%$ y pureza del $90 \%$; cuando se propaga por material vegetativo (estolones y cepas) y por semilla, tiene crecimiento estolonífero vigoroso y denso, es agresivo, poco compatible con leguminosas excepto Arachis pintoi y Desmodium ovalifolium; soporta alta carga animal en pastoreo, tolera los excesos de humedad en el suelo, pero no encharcamiento prolongado, además tolera la sequia, sin embargo en suelos arenosos disminuye su producción de forraje (Martínez et al., 2008), aunque resiste el ataque de plagas, en zonas muy húmedas es susceptible a la roya (Uromyces setaricae italicae) (Jimenez et al., 2010).

Como desventajas puede hospedar altas poblaciones del mión de los pastos que ocasiona daños severos, produce poca semilla viable y presenta latencia prolongada, su contenido de proteína cruda es bajo, lo cual afecta su consumo voluntario y la ganancia de peso, la calidad del forraje disminuye rápidamente a través del tiempo y la productividad animal es menor que en otras especies de Brachiaria (Cruz et al., 2011). 


\section{ESTRATEGIAS INTEGRALES DE CAMPO}

Actualmente en el Campo Rubiales y su zona de influencia existen áreas intervenidas para extracción de materiales con destino a obras de ingeniería, con una extensión estimada en 1300 hectáreas, que demandan la aplicación o implementación a corto y mediano plazo, de prácticas que permitan mitigar los efectos ambientales de la actividad petrolera, y cumplir con la normatividad ambiental, CORPOICA propuso desarrollar un plan de actividades para desarrollar estrategias para restablecer la capa vegetal en áreas descapotadas, taludes, cortes de serranía con plintita expuesta, mediante la aplicación de prácticas integrales de manejo como: recuperación de suelos, obras de geotecnia, establecimiento y mantenimiento de coberturas vegetales.

\section{Etapa de establecimiento para la recuperación de la capa vegetal}

Mediante una evaluación preliminar en campo se pudieron identificar tres categorías de áreas a intervenir donde se aplicaron prácticas de manejo agronómico de acuerdo a las condiciones de cada terreno. Las especies de coberturas que se utilizaron corresponden a gramíneas principalmente del genero Brachiaria con buena adaptación y desarrollo rápido en condiciones de la altillanura disectada colombiana (Tabla 3 ). Los requerimientos de correctivos a incorporar y semillas se determinaron con base a los análisis de suelo en las diferentes condiciones predominantes (Tabla 4), los fertilizantes comerciales recomendados se mezclaron bajo criterios de disponibilidad permanente de nutrientes que permitieran un buen desarrollo de los pastos (Tabla 5). Adicionalmente, se realizaron labores de siembras con material vegetativo en áreas no mecanizables (elevadas pendientes, montones de plintita y lodos sin extender) o en efecto, en procesos de resiembra manual. De acuerdo con las características de las áreas intervenidas el procedimiento de recuperación de la cobertura vegetal fue el siguiente: 
Tabla 3. Especies vegetales a evaluar en procesos de revegetación

\begin{tabular}{|c|c|c|}
\hline Especies & Nombre común & Característica \\
\hline B. humidicola & Pasto dulce & Estolonífera agresiva, requiere baja fertilidad. \\
\hline B. dictyoneura & Pasto llanero & $\begin{array}{l}\text { Estolonífera, menor agresividad, requiere } \\
\text { mediana fertilidad }\end{array}$ \\
\hline B. decumbens & Pasto amargo & $\begin{array}{l}\text { Crecimiento de macolla, baja agresividad, } \\
\text { requiere mediana fertilidad. }\end{array}$ \\
\hline
\end{tabular}

Tabla 4. Análisis de suelo para la recuperación de la cobertura vegetal

\begin{tabular}{ccc}
\hline Parámetro & Campo Rubiales & Área con lodos \\
\hline $\mathrm{pH}$ & 4.94 & 5.33 \\
$\mathrm{M} . \mathrm{O} .(\%)$ & 2.91 & 2.44 \\
$\mathrm{P}(\mathrm{ppm})$ & 2.9 & 2.0 \\
$\mathrm{Ca}(\mathrm{me} / 100 \mathrm{~g})$ & 0.91 & 1.02 \\
$\mathrm{Mg}(\mathrm{me} / 100 \mathrm{~g})$ & 0.23 & 0.11 \\
$\mathrm{~K}(\mathrm{me} / 100 \mathrm{~g})$ & 0.08 & 0.07 \\
$\mathrm{Na}(\mathrm{me} / 100 \mathrm{~g})$ & 0.04 & 0.06 \\
$\mathrm{Al}(\mathrm{me} / 100 \mathrm{~g})$ & 1.33 & 0.51 \\
$\mathrm{~B}(\mathrm{ppm})$ & 0.09 & 0.09 \\
$\mathrm{Cu}(\mathrm{ppm})$ & 0.84 & 0.80 \\
$\mathrm{Zn}(\mathrm{ppm})$ & 0.52 & 0.24 \\
$\mathrm{Fe}(\mathrm{ppm})$ & 189 & 492.24 \\
$\mathrm{Mn}(\mathrm{ppm})$ & 29.60 & 5.1 \\
\hline
\end{tabular}

Tabla 5. Fertilizantes utilizados en el proceso cobertura vegetal

\begin{tabular}{cc}
\hline Fertilizantes & Cantidad kg/ha \\
\hline Cal dolomita & $500-600$ \\
Roca fosfórica & $300-400$ \\
Yeso agrícola & $150-200$ \\
Abono paz del rio & $150-250$ \\
Urea & $75-100$ \\
Triple 15 & $75-100$ \\
DAP & $75-100$ \\
KCl & $75-100$ \\
\hline
\end{tabular}


Áreas descapotadas completamente: su cobertura vegetal y primeros perfiles del suelo han sido removidos por completo, dejando el subsuelo expuesto y representan cerca del 40 a $45 \%$ del área a intervenir. Presentan pendientes menores a $3 \%$ y no presentan barreras físicas para la mecanización, pero en términos de contenidos de minerales en el suelo puede restringir el desarrollo de especies herbáceas introducidas (Figura 4). En estas áreas descapotadas completamente se realizó una preparación del terreno e incorporación de insumos mediante un pase de cincel y/o un pase de rastrillo pulidor suave cuidando de no exponer el suelo a la erosión. De acuerdo con los requerimientos de las especies a establecer se estimó la aplicación de una mezcla de cal dolomita $500 \mathrm{~kg} / \mathrm{ha}$, roca fosfórica $300 \mathrm{~kg} / \mathrm{ha}$ y yeso agrícola $150 \mathrm{~kg} / \mathrm{ha}$ en el proceso de incorporación de enmienda.

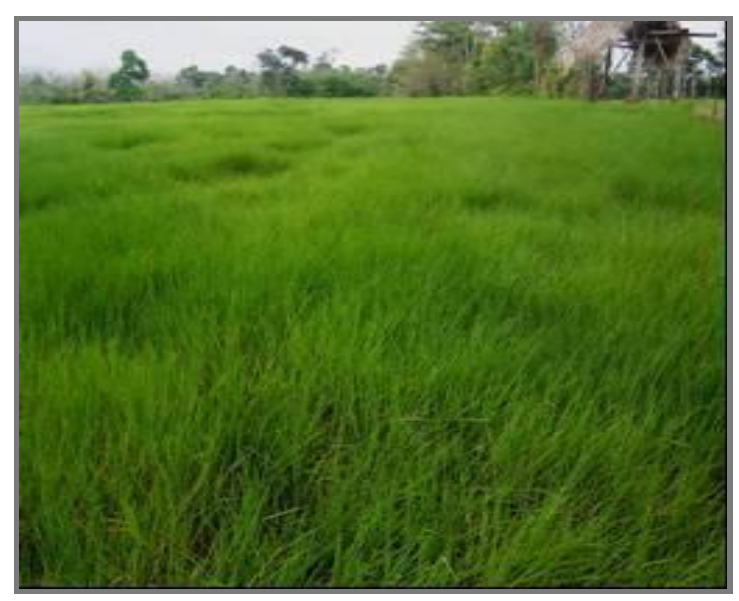

Figura 3. Pasto Brachiaria humidicola

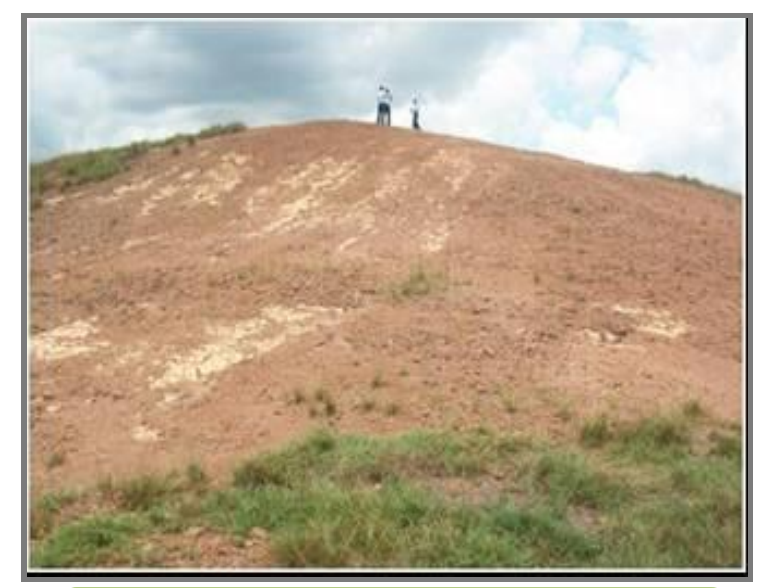

Figura 4. Áreas descapotadas completamente

La siembra se realizó con especies de gramíneas en monocultivo o en mezcla de materiales como: B. decumbens 2 a 3, B. humidicola 3 a 4 , y $B$. dictyoneura 3 a 4 $\mathrm{kg}$ de semilla por hectárea, calcificada y escarificada según el forraje. Estas especies se adaptan a condiciones de clima y suelo de la altillanura, también influyó para su establecimiento la calidad de la semilla o disponibilidad comercial y el hecho de que en algunos casos se utilizó material vegetativo (cepas y estolones). 
Áreas de serranía con plintita expuesta: su cobertura vegetal y parte de la capa de plintita ha sido removida, la cual por sus características físicas y químicas constituye una barrera compleja para la adecuación del terreno y el establecimiento y desarrollo de cualquier especie vegetal, puede presentar pendientes superiores a $3 \%$, ocupa un área aproximada del 40 a $45 \%$ del total (Figura 5).

En algunas partes de serranía con plintita expuesta se aplicó una capa de lodo, se preparó el terreno con un pase de rastra o rastrillo pulidor, aplicación e incorporación de enmienda para posteriormente realizar la siembra, la cual se realizó directamente con semilla o material vegetativo de las especies de cobertura (Tabla 3). En estas zonas se determinó la necesidad de realizar algunas obras de protección y adecuación (zanjas de drenaje y terrazas) que garantizaran la estabilidad del terreno, el establecimiento y persistencia de las coberturas con implementos agrícolas como caballoneadores y zanjadoras. El material proveniente de los cortes de perforación (lodos) se utilizó de acuerdo con los volúmenes y la facilidad de disposición en los sitios de trabajo por parte de Meta petroleum (Figura 6).

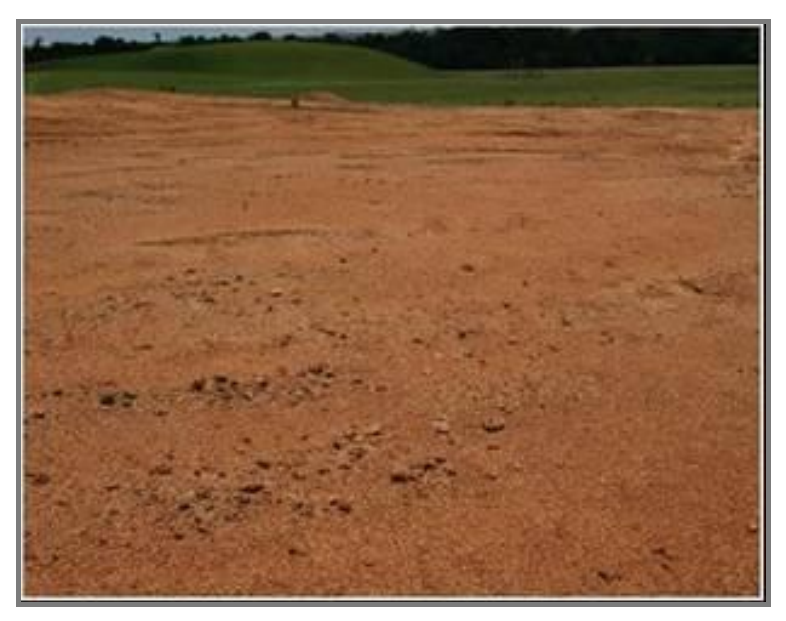

Figura 5. Áreas de serranía con plintita expuesta

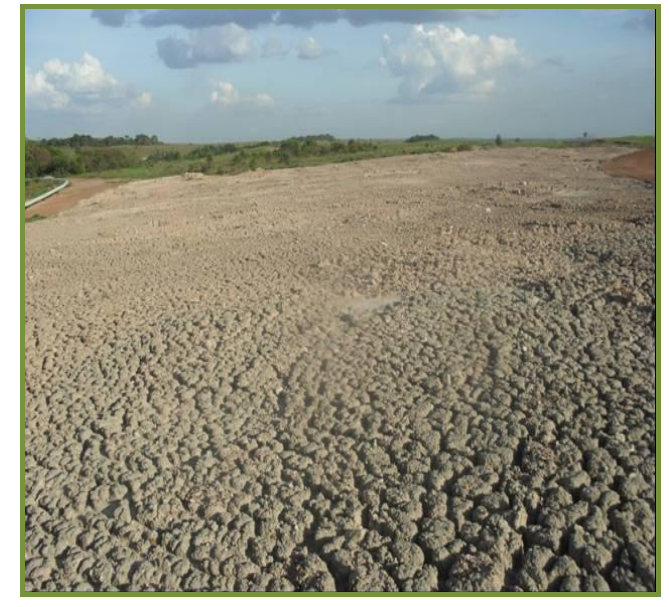

Figura 6. Áreas de serranía con lodos

Se inició labores de recuperación de la capa vegetal con la calibración de la encaladora con el fin de verificar la cantidad de fertilizantes y semillas a distribuir 
por hectárea, una vez preparado el suelo (rastra, rastrillo pulidor, cincel) se evaluó la profundidad efectiva para el desarrollo óptimo del sistema radicular de las pasturas. En cuanto a las obras de protección posterior a la siembra, se utilizó una zanjadora y un caballoneador con el fin de disminuir el arrastre de semilla e insumos por acción del agua, especialmente con zonas con pendiente pronunciada (Figura 7).

Culminadas las actividades de establecimiento de los lotes se llevó a cabo el geoposicionamiento satelital del área con GPS y su respectiva identificación en campo (tramo, locación y número de lote). De esta forma se conformó una base de datos tomados cada semana, con el fin de llevar registro e historial de cada lote con la información de campo de las áreas en proceso de recuperación, como: tramo, número de lote, cuantificación de área sembrada, fecha de siembra, mecanización del terreno, método de siembra y observaciones) (Tabla 6).

Tabla 6. Formato de información de áreas en proceso de recuperación

\begin{tabular}{|c|c|c|c|c|c|}
\hline Identificación & $\begin{array}{l}\text { Área } \\
\left(\mathrm{M}^{2}\right)\end{array}$ & Mecanización & Siembra & $\begin{array}{c}\text { Fecha } \\
\text { de } \\
\text { Siembra }\end{array}$ & Observaciones \\
\hline RB 161 RE1 & 1259 & $\begin{array}{l}\text { Dos pases } \\
\text { rastrillo pulidor }\end{array}$ & $\begin{array}{c}\text { Encaladora (Enmienda } \\
\text { +semilla; } B . \\
\text { decumbens y } B . \\
\text { dictyoneura) }\end{array}$ & $\begin{array}{c}18- \\
\text { Abril/10 }\end{array}$ & Área de Extracción \\
\hline RB 161 RE2 & 6431 & $\begin{array}{l}\text { Dos pases } \\
\text { rastrillo pulidor }\end{array}$ & $\begin{array}{c}\text { Encaladora (Enmienda } \\
\text { +semilla; B.decumbens } \\
\text { y B. dictyoneura) }\end{array}$ & $\begin{array}{c}11- \\
\text { Abril/10 }\end{array}$ & $\begin{array}{c}\text { Área con lodos; } \\
\text { Resiembra con mat. } \\
\text { vegetativo } \\
\text { (montones de lodos) }\end{array}$ \\
\hline RB 161 RE3 & 22315 & $\begin{array}{l}\text { Dos pases } \\
\text { rastrillo pulidor }\end{array}$ & $\begin{array}{c}\text { Encaladora (Enmienda } \\
\text { +semilla; } B . \\
\text { decumbens y } B . \\
\text { dictyoneura) }\end{array}$ & $\begin{array}{c}14- \\
\text { Abril/10 }\end{array}$ & $\begin{array}{l}\text { Área con lodos. } \\
\text { Resiembra con mat. } \\
\text { vegetativo } \\
\text { (montones con }\end{array}$ \\
\hline RB 161 RE4 & 8120 & $\begin{array}{l}\text { Dos pases de } \\
\text { escardillo } \\
\text { cruzado }\end{array}$ & $\begin{array}{c}\text { Encaladora (Enmienda } \\
\text { +semilla; } B . \\
\text { decumbens y } B . \\
\text { dictyoneura }\end{array}$ & $\begin{array}{c}08- \\
\text { Abril/10 }\end{array}$ & $\begin{array}{l}\text { Área de Extracción; } \\
\text { montones de lodos) }\end{array}$ \\
\hline
\end{tabular}

\section{Etapa de mantenimiento de áreas en proceso de recuperación}

Una vez realizado el establecimiento y toma de información de campo se llevó a cabo seguimiento de estas áreas con evaluaciones de germinación (30 y 60 días) 
y cobertura (120 días). Según los resultados de las evaluaciones se determinaron los requerimientos de fertilización y de resiembra, al tiempo se observó el crecimiento y desarrollo de las plantas, el vigor y los problemas fitosanitarios.

\section{Evaluaciones de germinación}

La evaluación de emergencia de los materiales establecidos en campo ( $B$. decumbens, $B$. humidicola y $B$. dictyoneura) se llevó a cabo mediante muestreos aleatorios representativos con un marco de $50 \mathrm{~cm} \times 50 \mathrm{~cm}$, a los 30 y 60 días después de la siembra (Figura 8). Teniendo en cuenta el conteo de plantas germinadas y plantas muertas, entre 10-20 muestreos por área dependiendo del tamaño del lote, la información se consignó de acuerdo a un formato de campo (Tabla 7).

Tabla 7. Formato de evaluación de germinación

\begin{tabular}{|c|c|c|c|}
\hline Lotes & $\begin{array}{c}\text { Plantas / } 5 \\
\mathrm{~m}^{2}\end{array}$ & $\begin{array}{l}\text { Plantas } \\
\text { / ha }\end{array}$ & Observaciones \\
\hline RB 161- RE1 & 110 & 220.000 & $\begin{array}{l}\text { Resiembra en zonas de alta } \\
\text { comparación }\end{array}$ \\
\hline RB 161- RE2 & 148 & 296.000 & $\begin{array}{l}\text { Plántulas amarillentas. } \\
\text { Fertilización }\end{array}$ \\
\hline RB 161- RE3 & 74 & 148.000 & Realizar drenajes \\
\hline RB 161- RE4 & 564 & 1.128 .00 & $\begin{array}{l}\text { Buena población de plántulas, buen } \\
\text { vigor. }\end{array}$ \\
\hline RB 161- RE5 & 104 & 208.000 & $\begin{array}{l}\text { La germinación no es homogénea. } \\
\text { Resiembra. }\end{array}$ \\
\hline RB 161- RE7 & 60 & 120.000 & Realizar drenajes \\
\hline RB 161- RE8 & 130 & 260.000 & Resiembra con material vegetativo \\
\hline
\end{tabular}

\section{Evaluaciones de cobertura}

Teniendo en cuenta las condiciones específicas de siembra de las áreas intervenidas, se determinó con la interventoría del proyecto un periodo de establecimiento de 120 días al final del cual se realizó la evaluación de cobertura 
de cada uno de los lotes para definir su entrega (Figura 9). Todas las evaluaciones de campo se realizaron con el interventor, y consistió en una valoración del porcentaje de cobertura, teniendo en cuenta un requerimiento mínimo del $70 \%$ de cobertura del suelo. Los lotes evaluados que no cumplían con el porcentaje exigido, se les daba un periodo adicional para lograr la cobertura, teniendo en cuenta la capacidad estolonífera de las especies establecidas (B. humidicola y $B$. dictyoneura).

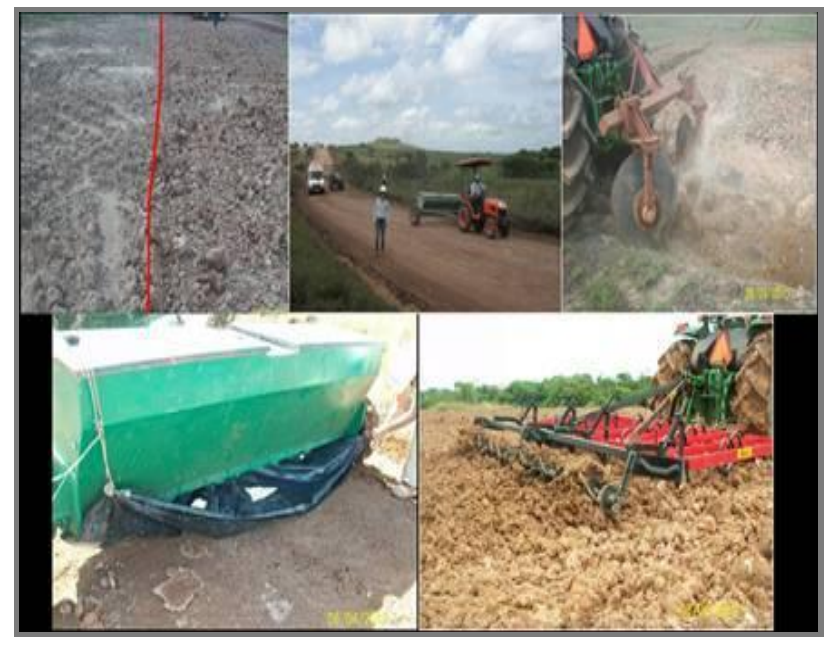

Figura 7. Evaluación y calibración de maquinaria agrícola

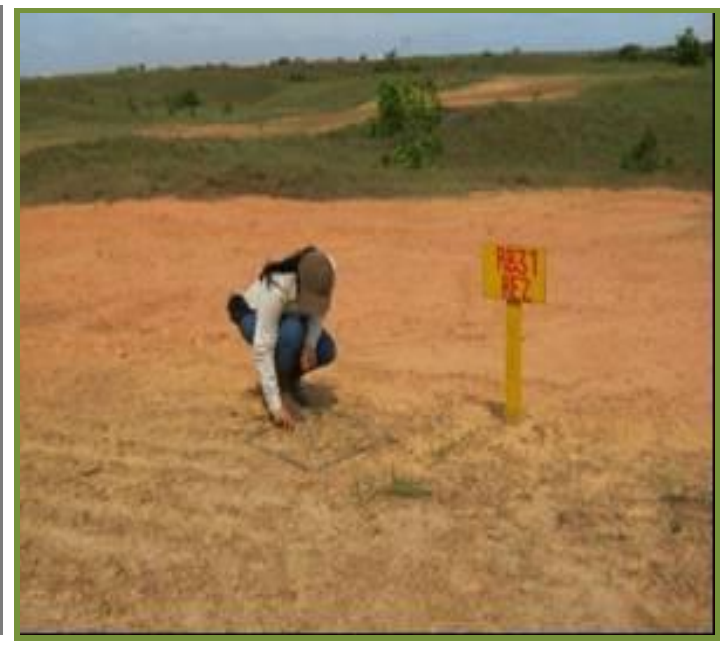

Figura 8. Evaluación de germinación en áreas de Revegetalización

\section{Fertilización}

Debido a que los lotes intervenidos son áreas de extracción que presentan limitantes químicos, físicos y biológicos se hizo necesario aplicar fertilizantes solubles durante la fase de establecimiento para garantizar un adecuado desarrollo de las especies (30 a 45 días de siembra dependiendo del régimen de lluvias de la zona) debido a que las fuentes utilizadas tienen mayor eficiencia cuando el suelo se encuentra con una humedad cercana a la capacidad de campo. Se emplearon fuentes solubles comerciales como Fosfato diamónico (DAP), Urea, y Cloruro de Potasio $(\mathrm{KCl})$ en relación 1:1:1 (50 kg) y dosis de 75 $\mathrm{kg} / \mathrm{ha}$ de la mezcla (Figura 10). Según las evaluaciones y observaciones en campo, se determinó el requerimiento de una segunda fertilización general o 
focalizada, la cual tuvo la misma composición de la primera e igual dosificación. Las áreas con pendientes pronunciadas fueron priorizadas con el fin de favorecer el desarrollo y anclaje de las plántulas, garantizando un mayor número de plantas y mejor cobertura, disminuyendo la vulnerabilidad del terreno por acción de la escorrentía.

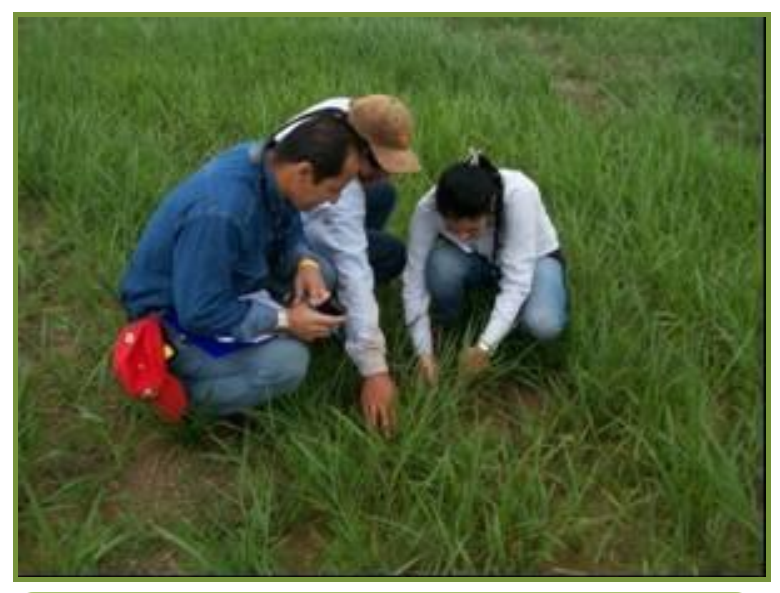

Figura 9. Evaluación de cobertura en áreas de Revegetalización

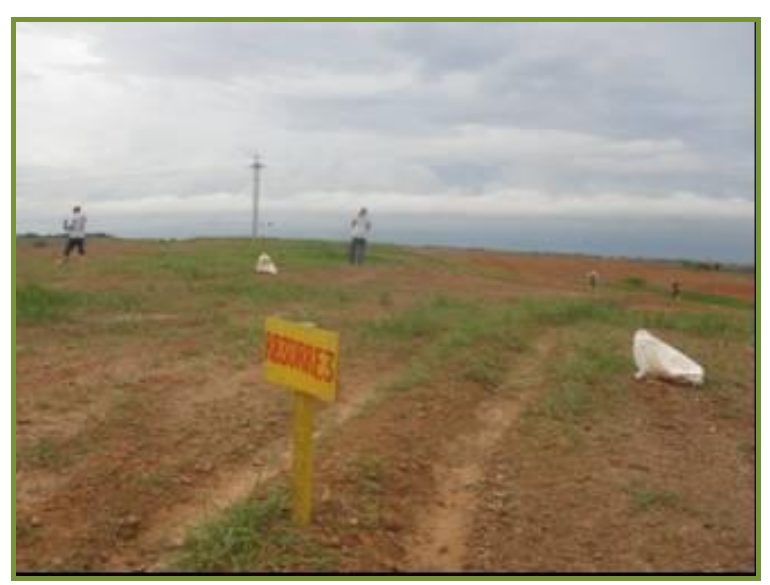

Figura 10. Fertilización general de áreas de Revegetalizadas

\section{Resiembra}

En la germinación en campo, se consideraron los resultados de las evaluaciones de variables como: densidad de población, crecimiento y desarrollo de las plantas, distribución y vigor, con lo cual se determinó la necesidad de resiembra. Según el tamaño del área, se definió el método de siembra utilizando semilla cariópside o material vegetativo (Figura 11).

\section{RESULTADOS Y DISCUSIÓN}

\section{Labores de preparación de terreno y siembra}

Las labores de siembra y el desarrollo de las actividades de recuperación de la capa vegetal en campo Rubiales se iniciaron a principios del mes de Abril del 2010 (comienzo de época de lluvias) y culminó a finales del mes de Octubre del 2010 cuando se empezó la temporada seca en la región. El proceso inició con la 
identificación y ubicación de áreas de extracción con plintita expuesta, áreas con lodos y áreas descapotadas completamente en los diferentes tramos priorizados, durante las primeras intervenciones se identificaron una serie de limitantes, siendo necesario efectuar ajustes en las prácticas agronómicas para asegurar una adecuada recuperación de la cobertura de las áreas. Para esto se consideraron aspectos básicos para el establecimiento de praderas, como la selección del lote y su topografía, las características fisicoquímicas del suelo, la precipitación anual y su distribución, selección de especies forrajeras a sembrar, prácticas de preparación y siembra, y previsión de problemas relacionados con ataque de plagas.

Así mismo y en concordancia con los anteriores aspectos, fue necesario evaluar otras alternativas de recuperación de la capa vegetal, acordes con las condiciones naturales propias de la zona asociadas a pendientes del terreno, alta precipitación y escorrentía superficial, además de algunos ajustes técnicos durante la fase de establecimiento como la inclusión de otra fuente de fosforo y la incorporación parcial de insumos para asegurar un mejor suministro o disponibilidad de nutrientes a las plantas en diferentes fases de desarrollo (Figura 12).

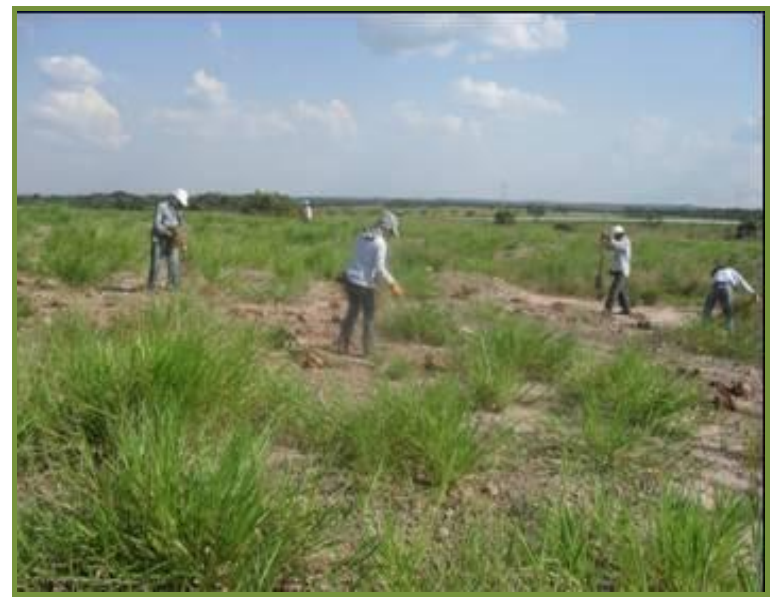

Figura 11. Resiembra parcial con material vegetativo en área con lodos

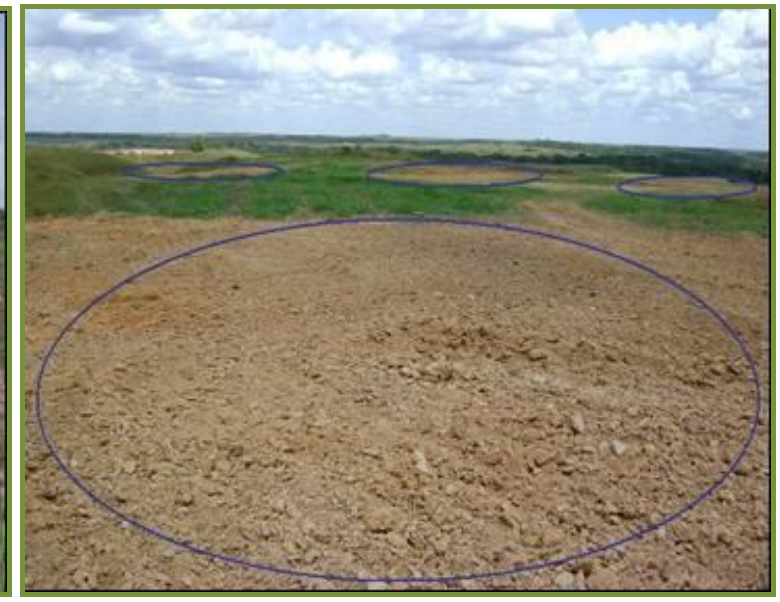

Figura 12. Resiembra parcial mecanizada con semilla en área de plintita expuesta 
Este proceso de ajuste se llevo a cabo en los primeros tramos establecidos (RB161 y RB116). En estos tramos se encontró condiciones heterogéneas de topografía, tamaño y forma de los lotes, presencia en áreas comunes de lodos, plintita expuesta y descapotadas que restringieron la ejecución definida para cada condición de suelo haciendo ineficiente las labores y generando la necesidad de unificar las practicas generales de preparación de suelos, fertilización y siembra (Figura 13).

En cuanto a las especies forrajeras para desarrollar los procesos de recuperación de cobertura vegetal se seleccionaron materiales como $B$. decumbens, $B$. humidicola y $B$. dictyoneura con base en su capacidad de adaptación, su rusticidad y persistencia en condiciones de alta saturación de aluminio y baja disponibilidad de nutrientes. Se utilizó una mezcla de $B$. decumbens con $B$. humidicola o con $B$. dictyoneura, teniendo en cuenta la rápida emergencia y cobertura de $B$. decumbens, complementada con la capacidad estolonífera y adaptación de $B$. humidicola y $B$. dictyoneura. En algunos lotes con alta saturación de humedad se privilegió la mezcla $B$. decumbens - $B$. humidicola a sabiendas que el $B$. decumbens desaparece prematuramente y queda el $B$. humidicola de buen comportamiento y desarrollo en estas condiciones. En consecuencia, el efecto del exceso de humedad fue notorio en áreas con lodos, especialmente sobre las plántulas de B. decumbens (Figura 14).
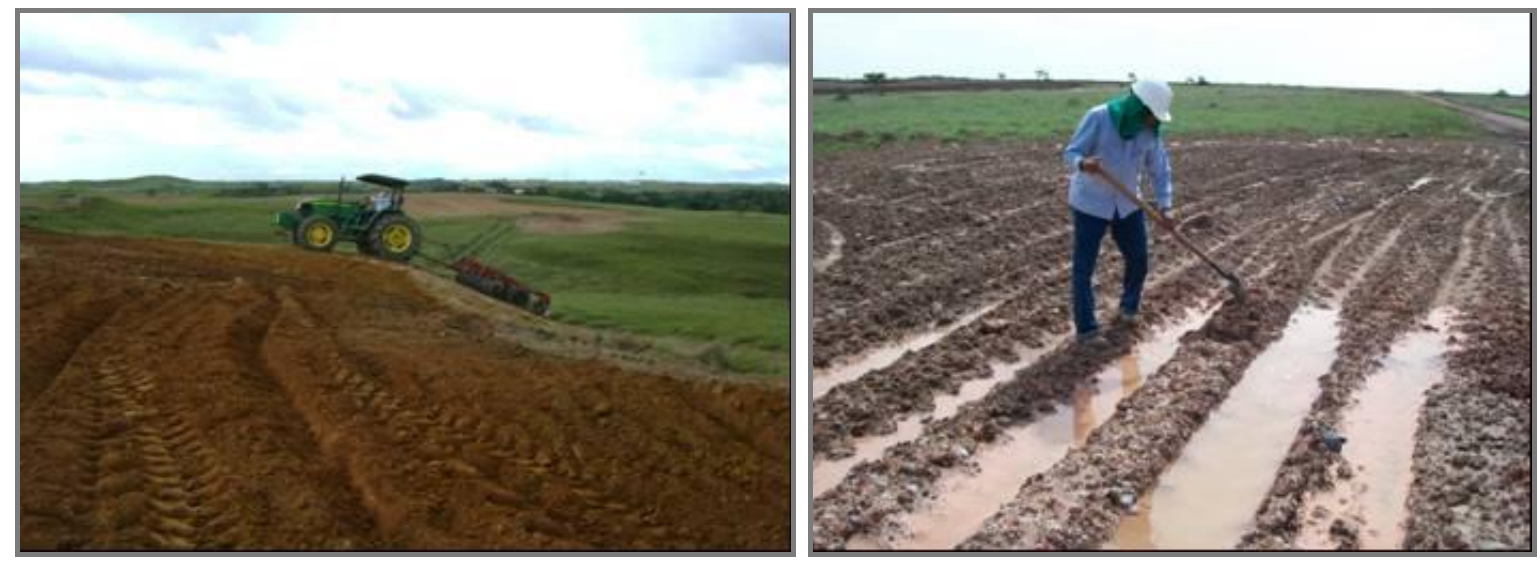

Figura 13. Topografía del terreno

Figura 14. Problemas de encharcamiento en área con lodos 
Los resultados indican que durante la fase de establecimiento (20 días después de la siembra) se presentó una moderada población de plántulas (5-6 plántulas $/ \mathrm{m}^{2}$ ). Este comportamiento se confirmó en una evaluación a los 60 días en donde predominaron las plántulas de $B$. humidicola y $B$. dictyoneura (Tabla 8).

Para contrarrestar el efecto del exceso de humedad y garantizar la supervivencia de las plantas existentes en áreas con lodos, se realizaron drenajes en algunas zonas, utilizando de acuerdo a la pendiente y la acumulación de agua, implementos agrícolas como caballoneador y zanjadora, para reducir la velocidad del agua de escorrentía y el movimiento de materiales (suelo, insumos, semillas) y así mismo reducir problemas de erosión. También se realizaron labores de fertilización focalizada y resiembras con material vegetativo con el fin de obtener una cobertura mínima del $70 \%$.

Por otro lado, el procedimiento de recuperación de la cobertura vegetal en áreas con plintita expuesta consistió en la preparación del suelo con dos pases de rastrillo de escardillo y la siembra con la encaladora aplicando $950 \mathrm{~kg} / \mathrm{ha}$ de una mezcla compuesta por $500 \mathrm{~kg}$ de cal dolomita $+300 \mathrm{~kg}$ de roca fosfórica $+150 \mathrm{~kg}$ de yeso agrícola y $7 \mathrm{~kg}$ de mezcla de semillas de gramíneas compuesta por $4 \mathrm{~kg}$ de $B$. decumbens $+3 \mathrm{~kg}$ de $B$. dictyoneura o B. humidicola.

En las primeras semanas de establecimiento en la mayoría de los lotes se mantuvo un porcentaje alto de germinación, buena población de plántulas y vigor; sin embargo, a los 60 días se observó una reducción en la población de plántulas, debido particularmente a las perdidas por arrastre de semillas o de plantas resultando mayor cobertura en zonas bajas con problemas de anclaje del sistema radicular.

Tradicionalmente en el establecimiento de una pastura, una vez preparado el lote se procede a realizar la siembra, utilizando una mezcla de los fertilizantes de establecimiento (roca fosfórica, cal dolomita, yeso agrícola) con las semillas, sin embargo, se modificó porque se hizo una preparación tradicional con rastra e incorporación de correctivos al suelo. Además, teniendo en cuenta los 
requerimientos nutricionales de las pasturas establecidas bajo condiciones de suelos ácidos, donde el fosforo $(\mathrm{P})$, es el mineral más limitante e influye en la capacidad del suelo de suplir nutrientes para asegurar un desarrollo rápido y vigoroso, se aumentó la aplicación de fertilizantes al momento de la siembra con fuentes de calcio y fosforo como el abono paz del rio (calfos).

El establecimiento se realizó de la siguiente forma: un pase de rastra, posteriormente se aplicaron los correctivos en dosis de $850 \mathrm{~kg} / \mathrm{ha}$ de una mezcla compuesta por $450 \mathrm{~kg}$ de cal dolomita $+250 \mathrm{~kg}$ de roca fosfórica $+150 \mathrm{~kg}$ de yeso agrícola, y luego se incorporó con un pase de rastra, finalmente se realizó la siembra con una mezcla de $150 \mathrm{~kg}$ de calfos $+50 \mathrm{~kg}$ de cal dolomita $+50 \mathrm{~kg}$ de roca fosfórica $+7 \mathrm{~kg}$ de mezcla de semillas de gramíneas ( $3 \mathrm{~kg}$ de $B$. decumbens $+2 \mathrm{~kg}$ de $B$. dictyoneura $+2 \mathrm{~kg}$ de $B$. humidicola). Con esta práctica de incorporación de correctivos se buscó dar una mejor distribución de los nutrientes en el perfil del suelo para reducir las posibles pérdidas por arrastre superficial de los materiales (semillas e insumos). En áreas con pendiente pronunciada, posterior a la siembra se realizaron obras de protección con caballones con el fin de disminuir el efecto de escorrentía del agua en el suelo.

En áreas completamente descapotadas fue necesario incrementar la fertilización al momento de la siembra adicionando $200 \mathrm{~kg} / \mathrm{ha}$ de calfos, logrando un mejor y rápido desarrollo de las plántulas antes de ser fertilizadas con fuentes solubles, garantizando una mayor cobertura y una reducción en las áreas de resiembra. Desde la primera evaluación de emergencia (20 días) se evidenció áreas con buena población de plantas, sin embargo, existieron zonas donde el crecimiento no fue el óptimo, por lo tanto, se requirió de resiembras focalizadas (Tabla 8).

El aumento de la cantidad de calfos al momento de la siembra permitió obtener buenos resultados en el proceso de emergencia de los materiales a los 20 días de establecimiento, y de esta forma realizar labores de fertilización temprana: entre los 30 a 45 días después de la siembra, con el fin de lograr la entrega oportuna de 
los lotes dentro del periodo de evaluación de 120 días, con un criterio mínimo del $70 \%$ de cobertura.

Tabla 8. Población de plántulas a los 20 y 60 días de edad en lotes de recuperación de la capa vegetal

\begin{tabular}{|c|c|c|c|c|c|c|}
\hline \multirow{3}{*}{$\begin{array}{l}\text { Identificación del } \\
\text { lote }\end{array}$} & \multicolumn{6}{|c|}{ Número de plantas/ha } \\
\hline & \multicolumn{2}{|c|}{ Suelo descubierto } & \multicolumn{2}{|c|}{ Plintita expuesta } & \multicolumn{2}{|c|}{ Lodos } \\
\hline & 20 días & 60 días & & & ías & 60 \\
\hline 1 & 450.0 & 00 & 00 & 23 & 148.000 & 12 \\
\hline 2 & 116.0 & 19 & 13 & & 74.000 & 90.000 \\
\hline 3 & 273.000 & 470.000 & 180.000 & 60.000 & 120.000 & 105.000 \\
\hline Promedio & $279.667^{a}$ & $286.667^{a}$ & $291.333^{a}$ & $132.667^{a}$ & $114.000^{a}$ & $105.333^{\circ}$ \\
\hline
\end{tabular}

${ }^{*}$ Promedios seguidos con la misma letra en la fila no presentan diferencia significativa según prueba de Tukey $(P>0,05)$

Para los lotes CLRE60 y CLRE61 se realizó la primera fertilización a los 35 días de la siembra, con una mezcla de $50 \mathrm{~kg}$ de urea, $50 \mathrm{~kg}$ de DAP y $50 \mathrm{~kg}$ de $\mathrm{KCl}$, y una dosis de $75 \mathrm{~kg} / \mathrm{ha}$ de la mezcla, para el RE75 se hizo una aplicación de 75 $\mathrm{kg} / \mathrm{ha}$ de una mezcla compuesta por $50 \mathrm{~kg}$ de agrimins (8-5-0-6), $15 \mathrm{~kg}$ de fosfitek (0-52-34) y $100 \mathrm{~kg}$ de Triple 15 a los 75 días después de la siembra, teniendo en cuenta la humedad óptima del suelo para que las plantas puedan absorber los nutrimentos, lo que permitió áreas con buen desarrollo y crecimiento de plantas, macollas vigorosas y capacidad estolonífera de los materiales.

\section{Germinación de materiales en campo}

Luego de las primeras intervenciones en campo, se escogieron aleatoriamente tres lotes por condición de suelo con el fin de verificar los resultados encontrados durante el proceso de establecimiento de las especies de cobertura bajo los procedimientos propios a las áreas a intervenir teniendo en cuenta la fase de emergencia, comportamiento y persistencia de los materiales en zonas con las limitaciones anteriormente descritas.

En relación con la población de plantas encontradas en los tres tipos de suelo intervenidos, no se encontró diferencias significativas $(P<0,05)$ entre los tipos de 
suelo a los 20 y 60 días de siembra (Tabla 8), sin embargo, se observó una variación en la población de plantas a diferentes edades de muestreo. Mientras que en áreas descapotadas completamente aumentó la población de plantas a los 60 días en relación con la población encontrada a los 20 días (286.667 vs. 279.667), en áreas con lodos y plintita expuesta disminuyó la población de plantas, comportamiento asociado posiblemente a varios factores como las condiciones contrastantes de suelo, variabilidad de pendientes, gradiente de humedad (escorrentía y encharcamiento) y disponibilidad de nutrientes. Con base en estos resultados se determinó ajustar las prácticas de recuperación de la cobertura vegetal acorde a las condiciones contrastantes propias de las áreas, teniendo en cuenta aspectos de relevancia como la selección de especies de cobertura, ubicación del lote y su topografía, época de preparación del terreno y siembra, tipo e intensidad de labranza, densidad de siembra, plagas, al igual que el manejo de los lotes en las primeras semanas después de la siembra, factores que en su conjunto favorecen un rápido y vigoroso desarrollo de las especies (Tabla 9).

Tabla 9. Recomendaciones técnicas para el establecimiento de gramíneas en tres tipos de suelos en recuperación

\begin{tabular}{|c|c|c|c|}
\hline $\begin{array}{c}\text { Dosis de insumos } \\
(\mathrm{kg} / \mathrm{ha})\end{array}$ & $\begin{array}{c}\text { Dosis de semilla } \\
(\mathrm{kg} / \mathrm{ha})\end{array}$ & Mecanización & Observaciones \\
\hline $\begin{array}{c}\text { Presiembra: } \\
\text { Cal dolomita } 450 \mathrm{~kg} / \mathrm{ha} \text {, } \\
\text { Roca Fosfórica } 250 \\
\mathrm{~kg} / \mathrm{ha} \text {, Yeso Agrícola } 150 \\
\text { kg/ha } \\
\text { Siembra: } \\
\text { Cal dolomita } 50 \mathrm{~kg} / \mathrm{ha} \text {, } \\
\text { Roca Fosfórica } 50 \mathrm{~kg} / \mathrm{ha} \text {, } \\
\text { Abono paz del rio } 150 \\
\mathrm{~kg} / \mathrm{ha} \text {. }\end{array}$ & $\begin{array}{c}\text { Dosis de semilla: } \\
7 \mathrm{~kg} / \mathrm{ha} \\
\text { B. decumbens } 3 \\
\mathrm{~kg} / \mathrm{ha} \\
\text { B. dictyoneura } 2 \\
\mathrm{~kg} / \mathrm{ha} \\
\text { B. humidicola } 2 \mathrm{~kg} / \mathrm{ha}\end{array}$ & $\begin{array}{c}\text { Rastra } 2 \text { a } 3 \\
\text { pases } \\
\text { uno para } \\
\text { preparación de } \\
\text { suelo y otro } \\
\text { para } \\
\text { incorporación } \\
\text { de enmienda) }\end{array}$ & $\begin{array}{l}\text { Posterior a la } \\
\text { siembra; en áreas } \\
\text { con pendientes } \\
\text { pronunciadas se } \\
\text { realizaron obras de } \\
\text { protección con } \\
\text { caballones y/o } \\
\text { zanjas. }\end{array}$ \\
\hline
\end{tabular}

Luego de haber efectuado los ajustes pertinentes en la metodología de establecimiento de especies de cobertura, se continuó con las labores de cobertura a partir del tramo RB 104, teniendo en cuenta la ejecución de obras adicionales como siembras con material vegetativo en áreas de difícil acceso (no 
mecanizables), obras de protección en áreas con pendientes pronunciadas con caballones y zanjas de drenaje, aumento de la dosis de calfos en áreas descapotadas completamente, y frecuencia de fertilización de áreas en recuperación de la capa vegetal (30-40 días después de la siembra) con el fin de entregar los lotes a los 120 días con un criterio mínimo del $70 \%$ de cobertura.

Culminando las actividades de cobertura, se llevó a cabo la evaluación del establecimiento en las tres condiciones de suelo (lodos, plintita y descapotadas), teniendo en cuenta que los procedimientos de intervención fueron similares para los tres. La labor de fertilización en todas las áreas no fue homogénea y se limitó de acuerdo con las condiciones de humedad del suelo asociadas a la precipitación en las áreas intervenidas. En muchos casos la falta de lluvia determinó la acumulación de áreas pendientes de fertilizar y afectó el número de plántulas, su vigor, viabilidad, la cobertura y la entrega oportuna de lotes dentro del periodo establecido.

En las áreas en donde se aumentó la cantidad de calfos al momento de la siembra y se realizó fertilización temprana, se logró coberturas de suelo superiores al $80 \%$ al cabo de la fase de establecimiento (120 días), principalmente en áreas descapotadas completamente (Figura 15).

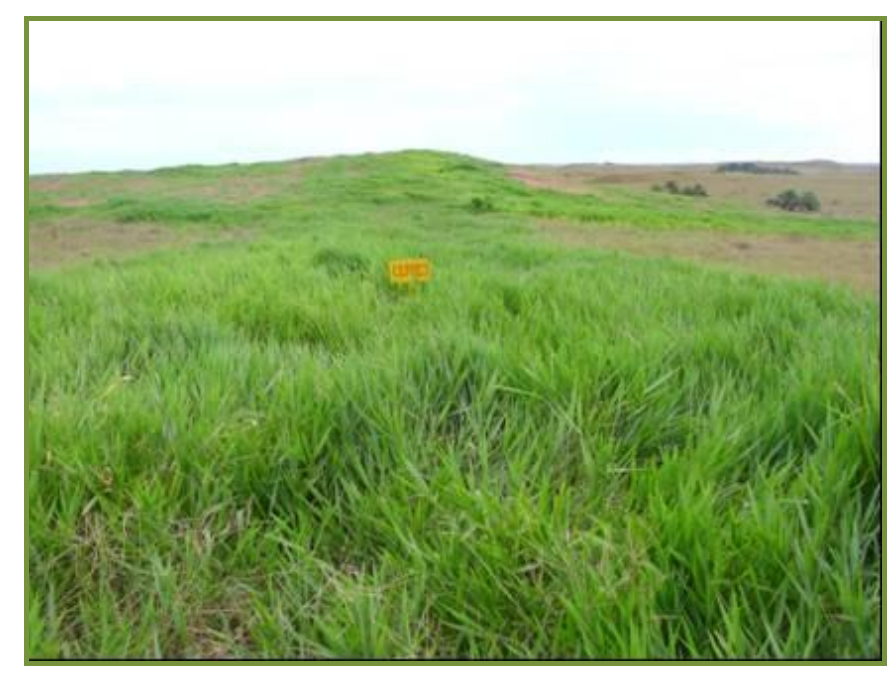

Figura 15. Área descapotada completamente con $90 \%$ de cobertura (120 días) 
Las variables agronómicas altura, cobertura y producción de forraje no fueron significativamente diferentes $(P>0,05)$ en condiciones contrastantes de suelo, sin embargo, es importante resaltar la edad a la cual se tomó la información en cada condición de suelo (Tabla 10). Cabe destacar el comportamiento de los materiales establecidos en áreas descapotadas en términos de cobertura de suelo y producción de forraje en un periodo relativamente corto (172 días).

\section{Áreas de recuperación de la cobertura vegetal}

En el año 2010 se alcanzaron a recuperar las 231,26 ha en campo Rubiales, distribuidas en 19 tramos o vías internas y 270 lotes. Además, se adelantaron labores de preparación temprana de suelo (incorporación de enmienda), alcanzado un total de 129 has mecanizadas para desarrollar la siembra. Aunque todos los 270 lotes cumplieron el tiempo requerido para la evaluación de cobertura (120 días de establecimiento), no todos pudieron ser entregados con base en el criterio de un mínimo del $70 \%$ de cobertura del suelo, del total de los lotes sembrados, 122 lotes correspondientes a 105.7 has pudieron ser entregados lo que representa al $46 \%$ del área total de trabajo (231,2 ha). El 54\% restante del área total sembrada correspondiente a 125.7 ha se entregó durante el año 2011 (Figura 16). Para asegurar una adecuada cobertura se determinó un tiempo adicional, siguiendo las recomendaciones específicas para cada área como resiembras y fertilizaciones generales, y focalizadas.

Tabla 10. Variables agronómicas de coberturas vegetales en tres condiciones de suelo al final de la fase de establecimiento, Rubiales.

\begin{tabular}{ccccc}
\hline Tipo de suelo & $\begin{array}{c}\text { Edad } \\
\text { (días) }\end{array}$ & $\begin{array}{c}\text { Altura } \\
\text { (cm) }\end{array}$ & $\begin{array}{c}\text { Cobertura } \\
\text { (\%) }\end{array}$ & $\begin{array}{c}\text { Forraje } \\
\text { (kgMS/ha) }\end{array}$ \\
\hline Área de lodos & 291 & 78,4 & 69,6 & 7731,7 \\
Área con plintita expuesta & 259 & 67,6 & 80,1 & 7069,6 \\
Área descapotada & 172 & 47,0 & 67,0 & 6553,3 \\
CV & - & 12,1 & 20,7 & 41,2 \\
Significancia & - & $\mathrm{ns}$ & $\mathrm{Ns}$ & $\mathrm{ns}$ \\
\hline
\end{tabular}

${ }^{*} \mathrm{~ns}=$ no significativa. $\mathrm{MS}=$ Materia seca 


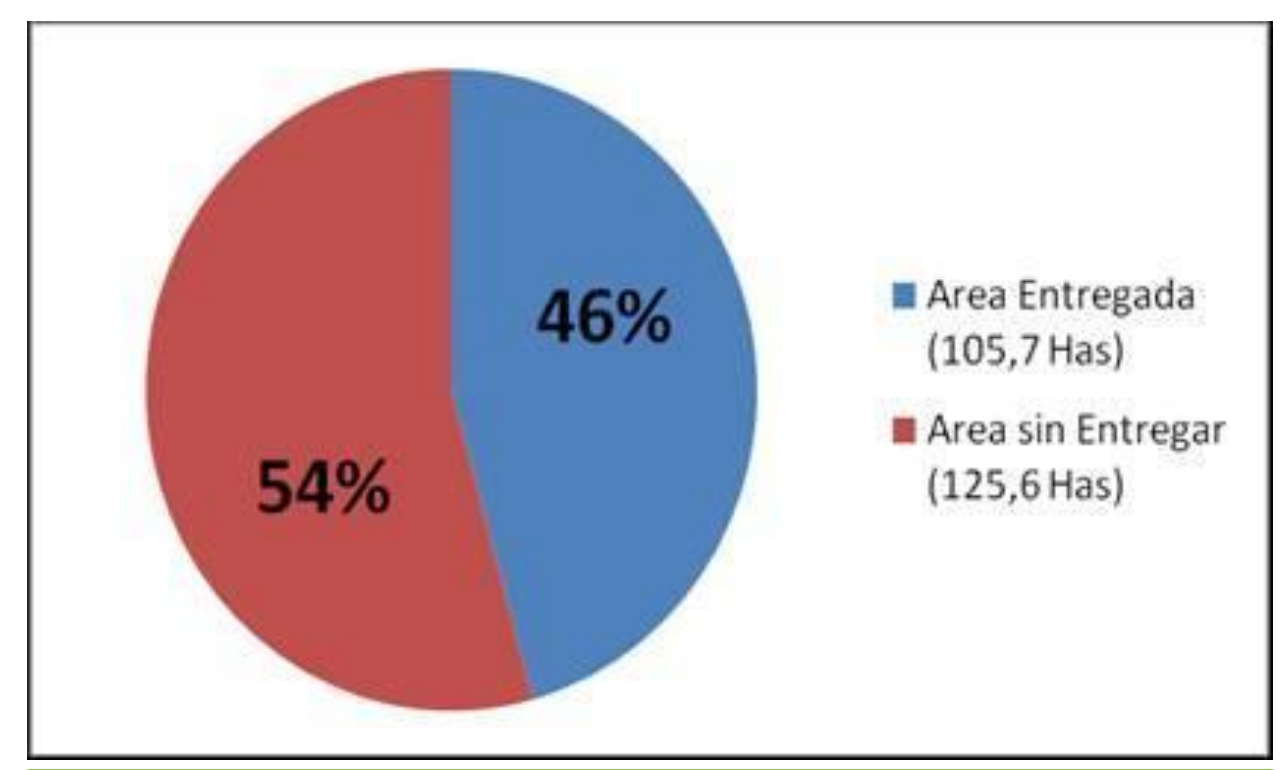

Figura 16. Estado de áreas revegetalizadas en campo Rubiales

Existen varios factores que determinaron la entrega de áreas formalmente a PRE, entre otras condiciones limitantes específicas de las áreas a intervenir, el sistema de siembra inicial, la perdida de plantas por escorrentía y encharcamientos, la demora en la aplicación de fertilizaciones de mantenimiento, la topografía con pendientes pronunciadas, todo esto dificultó y limitó el desarrollo y rendimiento de las labores de enmienda y fertilización. Las Figuras 17 y 18 ilustran el comportamiento de dos tipos se suelo (descapotado y con plintita expuesta), a los 120 días después de la siembra, bajo el nuevo sistema de establecimiento.

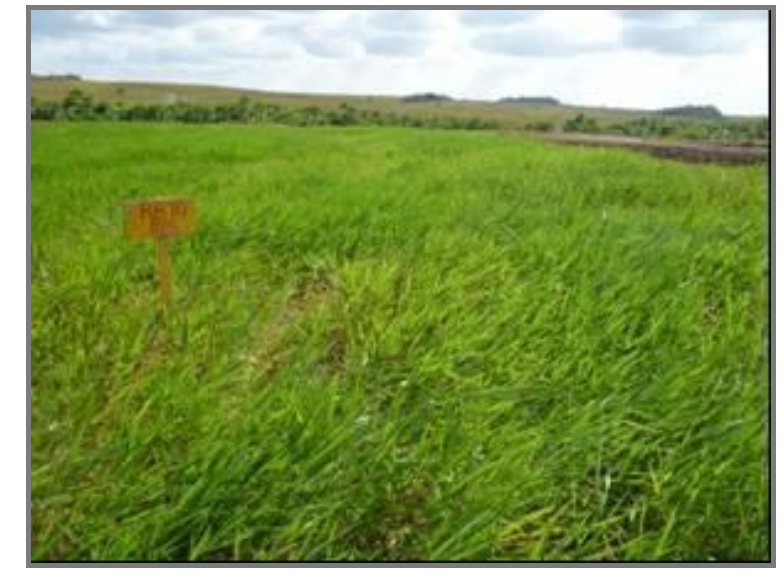

Figura 17. Evaluación de cobertura 95\% área descapotada (120 días)

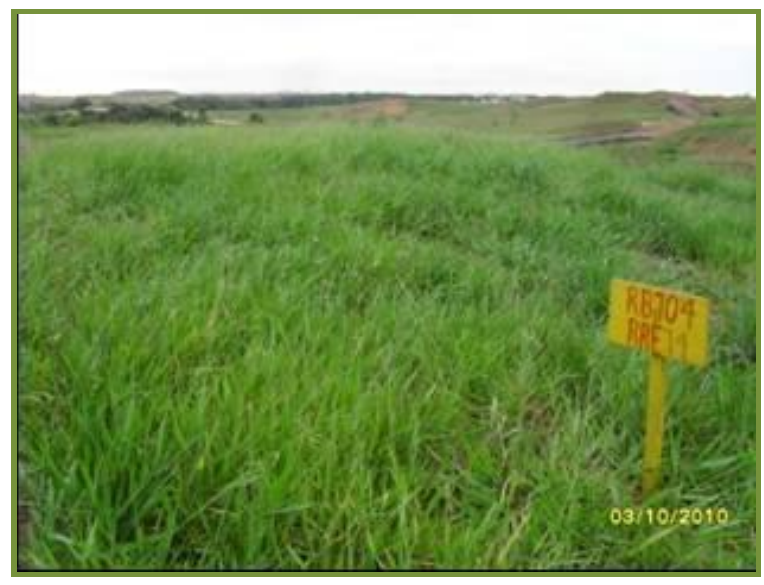

Figura 18. Evaluación de cobertura área con plintita expuesta 95\% (120 días) 


\section{Preparación temprana de lotes}

Una vez finalizadas las labores de siembra en octubre de 2010, se iniciaron las actividades de preparación temprana de lotes durante los meses de noviembre y diciembre al final de la época de lluvias. Además de hacer un uso más eficiente del tiempo y adelantar actividades sobre áreas a intervenir durante el año 2011, a través de esta práctica se buscó controlar algunas plagas como las hormigas cortadoras (Atta sp y $A$. landolti) que afectan el establecimiento de pastos en condiciones de la altillanura, además se estimuló la mineralización de la materia orgánica incorporando $(\mathrm{Ca}, \mathrm{P}, \mathrm{Mg}, \mathrm{S})$ mejorando la condición del suelo para la siembra de especies de cobertura

\section{CONCLUSIONES}

Es necesario planificar las actividades de preparación de suelos, obras de geotecnia, siembra, niveles y épocas de fertilización para asegurar los procesos de recuperación de la cobertura vegetal.

La incorporación parcial de fuentes de fosforo como el calfos en el proceso de ajuste de las prácticas de establecimiento dieron buenos resultados en las áreas a recuperar, mejorando el suministro y/o disponibilidad de nutrientes para las plantas en diferentes fases de desarrollo, asegurando la entrega oportuna de los lotes a los 120 días de siembra con criterio del 70\% mínimo de cobertura.

Los materiales forrajeros seleccionados en el proceso de recuperación ( $B$. decumbens, $B$. dictyoneura y $B$. humidicola), demostraron adaptación a las condiciones edafoclimáticas de la zona.

\section{RECOMENDACIONES}

La fertilización temprana de los lotes con fuentes solubles puede ayudar a contrarrestar efectos negativos como la escorrentía sobre las plántulas, pues se puede lograr su desarrollo más rápido y vigoroso, además se mejora el anclaje, mayor población de plantas por unidad de área, teniendo en cuenta el momento 
de la fertilización la cual debe realizarse entre los 30-45 días después de la siembra, sin embargo, esta labor está determinada por las condiciones de humedad del suelo asociadas a la precipitación.

\section{REFERENCIAS BIBLIOGRÁFICAS}

1. Belalcázar D. J., Lemus L. H., Duran C. V. Especies forrajeras tropicales de interés para pasturas en suelos ácidos de Colombia. Cali: CIAT. 1995.

2. Chacón C. A. Evaluación de pasturas de Brachiaria humidicola sola y en asociación con Desmodium ovalifolium, en sistema de pastoreo rotativo, al norte del estado de Táchira. IX Seminario de pastos y forrajes. p 138-149. 2005.

3. CIAT. Agroecología y biodiversidad de las sabanas de los llanos orientales de Colombia. Rippstein G., Escobar G. y Motta F (Ed). Publicación N. 322, 302 p. 2001.

4. CIAT. Establecimiento y renovación de pasturas. Memorias VI Reunión del Comité asesor de la RIEPT. Veracruz, México 425 p.1988.

5. CIAT. Manejo y Utilización de Pasturas en Suelos Ácidos de Colombia. En: Unidades de Aprendizaje para la Capacitación en Tecnología de Producción de Pastos. 1994.

6. Cruz P. I., Hernández G. A., Enríquez Q. J., Mendoza P. Sergio I., Quero C. A., Bertín M. J. Desempeño agronómico de genotipos de Brachiaria humidicola (Rendle) Schweickt en el trópico húmedo de México. Rev. Fitotec. Mex., 34 (2): 123-131, 2011.

7. Ernst, O. Leguminosas como cultivo de cobertura. Informaciones Agronómicas del Cono Sur. N. 21.9 p. 2004.

8. Faria M. J. Manejo de pastos y forrajes en la ganadería doble propósito. Universidad de Zulia. X Seminario de Pastos y Forrajes, p 1-9. 2006.

9. Franco Q. L., Calero D. Duran C. Manual de Establecimiento de Pasturas, Proyecto: Evaluación de tecnologías por métodos participativos para la implementación de sistemas ganaderos sostenibles en el norte del departamento del Valle del Cauca. Centro Internacional de Agricultura Tropical (CIAT): Universidad Nacional de Colombia - Sede Palmira, 27 p. 2005.

10. Gómez B. C. Conocimiento local, diversidad biológica y desarrollo. En: J. Labrador-Moreno, M. Altieri (Eds) Agroecología y Desarrollo. Aproximación a los Fundamentos Agroecológicos para la Gestión Sustentable de Agrosistemas Mediterráneos. Univ. de Extremadura y Ediciones MundiPrensa, Cáceres, Madrid, p 49-64. 2001.

11. Instituto Geográfico Agustín Codazzi. Análisis geográficos N. 26. Neógeno y cuaternario del altiplano de Bogotá y sus alrededores. Thomas Van Der Hammen. Ed Científico, Bogotá. 2003

12. Jaramillo C. F. Crisis y transformaciones de la agricultura colombiana: 19902000. Banco de la República. Bogotá D.C. 2002. 
13. Jiménez O. M., Granados L., Oliva J., Quiroz J., Barrón M. Calidad nutritiva de Brachiaria humidicola con fertilización orgánica e inorgánica en suelos ácidos. Archivos de Zootecnia, 59, (228). 2010.

14.Jorba M., Ninot J. M., Vallejo R. Las siembras en la revegetación de zonas afectadas por minería. Universidad de Barcelona. Rev Ingeopes, 166: 30-35. 2007.

15. Keller G. G., Maass B. L., Hanson J. Natural variation in Brachiaria and existing germplasm collections. En: Brachiaria: biology, agronomy and improvement. Miles, J.W.; Maass, B.L. \& do Valle, C.B. (Eds.). Centro Internacional de Agricultura Tropical. Cali, Colombia. p 16. 1996.

16. Lascano C. E., Avila P., Quintero C. I., Toledo J. M. Atributos de una pastura de Brachiaria dictyoneura - Desmodium ovalifolium y su relación con la producción animal. Revista Pasturas Tropicales, 13, (2): 10-20. 1991.

17. Navarro G., H.; Pérez O. M.A.; Castillo G., F. Evaluación de cinco especies vegetales como cultivos de cobertura en valles altos de México. Revista Fitotecnia Mexicana. 30 (2): 151-157, 2007.

18. Martínez M. D., Hernández G. A., Enríquez Q. J. F., Pérez P. J., González M. S., Herrera H. J. G. Producción de forraje y componentes del rendimiento del pasto Brachiaria humidicola CIAT 6133 con diferente manejo de la defoliación. Rev. Téc Pecu Méx., 46 (4): 427-438. 2008.

19. Maya G. La gratuidad de la minería. Diario El Tiempo, 15 Abril 2012.

20. Olivera Y., Machado R., del Pozo P. Características botánicas y agronómicas de especies forrajeras importantes del género Brachiaria Pastos y Forrajes, 29 (1): 1-13. 2006.

21. Osorno H. H. Mitos y realidades de las cales y enmiendas en Colombia. Trabajo de grado para optar al título MSc Ciencias, geomorfología y suelos. Universidad Nacional de Colombia, p. 70. 2012.

22. Pérez B., R.; Rincón A.; Bueno G.; Vargas O.; Cuesta P. Alternativas de establecimiento de praderas. Corporación Colombiana de Investigación Agropecuaria, CORPOICA. Innovación y Cambio Tecnológico, 1 (2): 56-61. 2000.

23. Pérez M., Morillo M., Malpica L. Eficiencia de cuatro especies de Centrosema para utilizar fósforo de la roca fosfórica Riecito en suelos con diferentes capacidades de retención de fósforo. Rev. Zootecnia Tropical, 27 (3): 239-247. 2009.

24.Pérez L., O.; Pérez B. R. Informe final proyecto Evaluación agronómica y productiva de especies forrajeras en la Orinoquia Colombiana. CORPOICA. C.I. La Libertad. Villavicencio. Meta. 45 p. 2003.

25. Pérez B. R. A., Cuesta M. P. A. Especies Forrajeras para el Piedemonte Llanero. Manejo y Producción Animal. Pastos y Forrajes para Colombia. Suplemento Ganadero. ICA Banco Ganadero p 85-94. 1992.

26. Pulido C., S.X.; Jaramillo S., C.A.; Corredor M., M. Caracterización socioeconómica de las comunidades indígenas Wacoyo y Awaliba del Municipio de Puerto Gaitán, Meta. Disponibles En: http://www.corpoica.org.co/SitioWeb/Archivos/oferta/CARACTERIZACIONSOC IOECONOMICA.pdf 
27. Ramírez J. L., Herrera R.S., Leonard I. Verdecia D., Álvarez Y. Rendimiento y calidad de la Brachiaria decumbens en suelo fluvisol del Valle del Cauto, Cuba. REDVET - Revista Electrónica de Veterinaria, 13 (4). 2012.

28. Rincón C. A. Degradación y Recuperación de Praderas en los Llanos Orientales de Colombia. Boletín Técnico N. 19. CORPOICA - PRONATTA. Villavicencio. Meta. Colombia. 48 p. 1999.

29. Rincón A.; Cuesta P.; Pérez R.; Bueno G.; Pardo O.; Gómez J. Manual técnico Producción y utilización de recursos forrajeros en sistemas de producción bovina de la Orinoquia y el Piedemonte Caqueteño. CORPOICA-FEDEGANMADR. Santafé de Bogotá. Colombia. 76 p. 2002.

30. Rincón C. A. Factores de degradación y tecnología de recuperación de praderas, Llanos orientales de Colombia. Boletín Técnico No. 49. Transferencia de tecnología CORPOICA C.I. La libertad. Editora Guadalupe LTDA, Segunda edición, 2006.

31. Rincón C. A. Efecto de alturas de corte sobre la producción de forraje de Brachiaria sp. en el piedemonte Llanero de Colombia. Revista Corpoica Ciencia y Tecnología Agropecuaria, 12 (2): 107-112. 2011.

32. Rojas H. S., Olivares P. J., Jiménez G., Gutiérrez S. I., Avilés N. F. Producción de materia seca y componentes morfológicos de cuatro cultivares de Brachiaria en el trópico. Avances en Investigación Agropecuaria, 15 (1): 3-8. 2011.

33. Tormo B. J., Bochet S. E., García F. P. El estudio de los factores que limitan la colonización vegetal en estas áreas degradadas puede ayudar a mejorar las técnicas de revegetación. Revistas - Ecosistemas, 18 (2): 79-90. 2009.

34. Teasdale I, Devine T, Mosjidis J, Bellinder R., Beste C. Growth and development of hairy vetch cultivars in the Northeastern United States as influenced by planting and harvesting date. Agronomy Journal, 92:1266-1271. 2004.

35. Teasdale J. R. Principios y prácticas para el uso de cultivos de cobertura en el manejo de sistemas de malezas. In: Manejo de malezas para países en desarrollo (Addenduml). R. Labrada (ed) FAO - ONU. 2004. Disponible En: http://www.fao.org/3/y5031s/y5031s0j.htm

36. Uribe F., Zuluaga A.F., Valencia L., Murgueitio E., Zapata A., Solarte L., et al. Establecimiento y manejo de sistemas silvopastoriles. Manual 1, Proyecto Ganadería Colombiana Sostenible. GEF, BANCO MUNDIAL, FEDEGAN, CIPAV, FONDO ACCION, TNC. Bogotá, Colombia. 78 p. 2011.

37. Vera R. R., Hoyos P., Ramírez G. Stylosanthes capitata en pasturas asociadas: Dinámica, persistencia y recuperación en los Llanos Orientales de Colombia. Revista Pasturas Tropicales, 19, (2): 21-34. 1997.

38.Zapata, F. FAO/IAEA research activities on direct application of phosphate rocks for sustainable crop production. En: S.S.S. Rajan y S.H. Chien, (Eds.). Direct application of phosphate rock and related technology: latest developments and practical experiences. Proc. Int. Meeting, Kuala Lumpur, 1620. Muscle Shoals, USA, IFDC. 441 pp. 2003. 